\title{
Analysis of the natural radon progeny contribution to radioactive aerosol monitoring in the automatic Spanish surveillance network
}

\author{
D. Arnold, A. Vargas, G. Cortés \& X. Ortega \\ Institut de Tècniques Energètiques (INTE), \\ Universitat Politècnica de Catalunya, Spain
}

\begin{abstract}
Continuous monitoring of radioactive pollutants in the air is provided by environmental radiological surveillance networks. In Spain, continuous and automatic control is carried out by the REA network, which comprises a set of 25 automatic stations. Most of these stations are run together with meteorological stations, belonging to the Spanish Meteorological Institute. The monitor for measuring the artificial radioactive aerosol concentration is the BAI 9850 from Berthold Company. An important contribution to the uncertainty of its measurements is due to natural air radioactivity, mainly from radon progeny. A statistical study using the data from the REA and the INM radiological and meteorological stations has been carried out in order to characterize the natural radioactivity at each station and to improve the quality of the artificial radioactivity air concentration measurements. This study shows that natural radioactivity concentration varies both daily and seasonally, and is significantly correlated to meteorological parameters and the geological properties of station surroundings. Radon progeny concentration commonly shows a daily cycle with a maximum in the early morning and a minimum in the afternoon, according to the behaviour of meteorological parameters. However, at a station situated at a higher altitude, the radon progeny pattern is completely different, due to the evolution of the planetary boundary layer above this complex terrain. Stations have been classified into coastal, inland and mountain according to the behaviour of the natural radioactivity at each location. A representative station from each category has been selected and a simulation study is being carried out using the MM5 code coupled with the atmospheric transport code FLEXPART.

Keywords: radon, radioactive pollutants, radiological surveillance.
\end{abstract}




\section{Introduction}

The Spanish environmental radiological surveillance is mainly carried out by the Spanish Nuclear Safety Council (Consejo de Seguridad Nuclear, CSN) [1] through the REVIRA (Red de Vigilancia Radiológica Ambiental) program. This program includes a set of sampling stations (REM) and a continuous radioactive pollutant monitoring network (REA). The REA network, Vila et al. [2], consists of 25 automatic radiological stations distributed all over the Spanish region including one in Portugal which are run together with meteorological stations belonging to the Spanish National Meteorological Institute (Instituto Nacional de Meteorología, INM) [3]. Stations provide gamma dose rate, radon concentration, radioactive iodine, alpha and beta air concentration and meteorological data. In addition, some of the Spanish autonomous communities have their own radiological surveillance network and, through bilateral agreements, their data is continuously sent to the CSN.
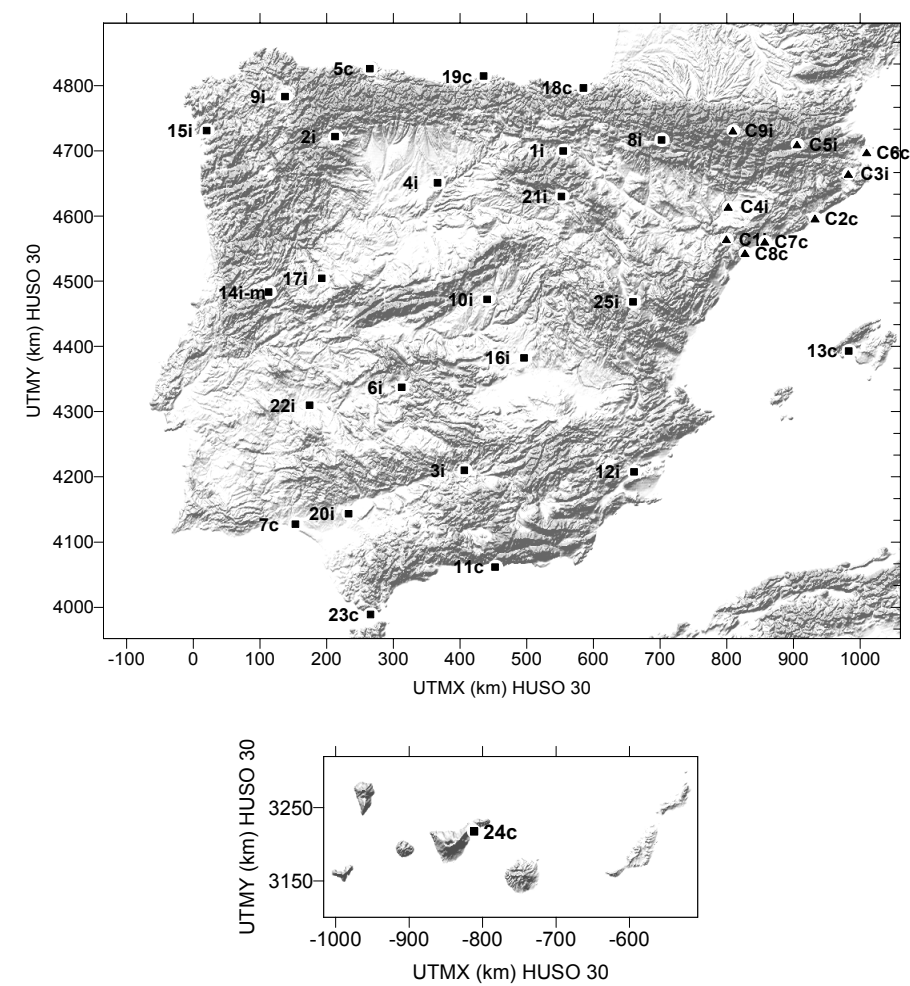

Figure 1: Distribution over the Iberian Peninsula and the Canary Islands of the REA monitoring stations ( $\boldsymbol{\square})$ and the SCAR monitoring stations (A) with their identification label and type (inland i, inlandmountain i-m, or coastal c). 
The main aim of these networks is the detection of possible artificial radioactive emission into the atmosphere, but natural air radioactivity is also measured at the stations and contributes to the uncertainty in the artificial activity detection, especially when the latter is low. Therefore, knowledge of natural air radioactivity behaviour becomes necessary in order to evaluate its contribution to the uncertainty.

The most significant source of natural background radioactivity is radon and its decay products. Once radon is exhaled from the ground into the planetary boundary layer, its airborne radon progeny and radon itself are subjected to atmospheric dispersion processes limited by radioactive decay and dry and wet deposition. Atmospheric transport, which is mainly determined by the evolution of meteorological parameters, leads to temporal variations in natural background radioactivity. Therefore, a statistical study has been carried out to characterize radon and radon progeny natural concentrations and their local variability in order to improve the quality of REA operability. The following sections will show some of the results obtained from the analysis of the monitoring data collected in the period 2000 through 2002 including a brief description of the station sites and equipment.

\section{Instrumentation and methodology}

\subsection{Site description}

The location of the REA stations and those belonging to the Catalan Radiological Activities Control Service (Servei de Coordinació d'Activitats Radiològiques, SCAR, Catalan Autonomous Community, in the north-east of the Iberian Peninsula) are presented in table 1.

\subsection{Equipment and measurement procedure}

Each REA station is provided with an automatic meteorological station (EMA) and an automatic radiological station (ERA). The EMA has the necessary instrumentation to measure relative air humidity, temperature, wind direction and velocity, rain, solar radiation and atmospheric pressure. The ERA consists of a LB 9850D monitor from Berthold Company, which includes modules for particle detection (BAI 9300), radioactive iodine detection (BAI 9311) and an outdoor dual Geiger-Müller tube detector system (BAI 9309) to measure the gamma dose rate. This monitor continuously pumps in outdoor air at approximately $5 \mathrm{~m}^{3} \mathrm{~h}^{-1}$ through a moving glass-fibre filter where aerosol particles are retained. The superficial alpha and beta disintegrations and the pseudocoincidences due to ${ }^{214} \mathrm{Po} /{ }^{214} \mathrm{Bi}$ simultaneous decay are detected by a $\mathrm{ZnS}$ plastic scintillator system. The artificial radioactivity concentration is obtained by subtracting the natural contribution, obtained from the pseudocoincidences, from the total alpha counts. In such a measurement system, the temporal variation of radon progeny equilibrium leads to temporal variation of a background signal in the artificial radioactivity as has been described in Vargas et al. [4]. Thus, for correct 
measurement, the radioactive particles deposited in the filter from five hours previously should be taken into account because of the filter movement. The solution of the monitor response modelling shows that obtained radon progeny concentration has a one-hour delay. This has been checked by comparing the measurements with those obtained by an alpha spectrometer device, which was self developed here at the INTE, as can be seen in figure 2 .

Table 1: $\quad$ Station label (coastal c, inland i, inland subgroup mountain i-m), name, UTM coordinates, height above sea level, and the meteorological (EMA) and radiological (ERA) operability of REA and SCAR (shaded grey) monitoring stations.

\begin{tabular}{|c|c|c|c|c|c|c|}
\hline \multirow{2}{*}{$\begin{array}{c}\text { Station } \\
\text { label }\end{array}$} & \multirow{2}{*}{ Station name } & \multirow{2}{*}{$\begin{array}{c}\text { UTMX } \\
\text { (m) }\end{array}$} & \multirow{2}{*}{$\begin{array}{c}\text { UTMY } \\
\text { (m) }\end{array}$} & \multirow{2}{*}{$\begin{array}{c}\text { Height } \\
\text { (m) }\end{array}$} & \multicolumn{2}{|c|}{ Operability } \\
\hline & & & & & ERA & EMA \\
\hline $\mathbf{1 i}$ & Agoncillo & 554849 & 4699957 & 353 & $94 \%$ & $75 \%$ \\
\hline $2 \mathbf{i}$ & Almázcara & 211467 & 4722395 & 584 & $90 \%$ & $78 \%$ \\
\hline $3 \mathbf{i}$ & Andújar & 406357 & 4209681 & 212 & $86 \%$ & $87 \%$ \\
\hline $4 \mathbf{i}$ & Autilla del Pino & 367490 & 4651014 & 860 & $88 \%$ & $80 \%$ \\
\hline $5 c$ & Avilés & 255307 & 4828244 & 20 & $76 \%$ & $85 \%$ \\
\hline $6 \mathbf{i}$ & Herrera del Duque & 321428 & 4337344 & 460 & $88 \%$ & - \\
\hline $7 \mathrm{c}$ & Huelva & 152704 & 4133465 & 20 & $87 \%$ & $83 \%$ \\
\hline $8 \mathbf{i}$ & Jaca & 701046 & 4717419 & 820 & $83 \%$ & $90 \%$ \\
\hline $9 \mathbf{i}$ & Lugo & 137953 & 4783427 & 446 & $86 \%$ & $75 \%$ \\
\hline $10 \mathbf{i}$ & Madrid & 439200 & 4477952 & 670 & $89 \%$ & $88 \%$ \\
\hline $11 \mathrm{c}$ & Motril & 452400 & 4063611 & 3 & $75 \%$ & $81 \%$ \\
\hline $12 \mathbf{i}$ & Murcia & 660939 & 4207400 & 61 & $87 \%$ & $98 \%$ \\
\hline $13 c$ & Palma de Mallorca & 982745 & 4392908 & 3 & $95 \%$ & $97 \%$ \\
\hline 14i-m & Penhas Douradas & 113059 & 4483319 & 1382 & $77 \%$ & $76 \%$ \\
\hline $15 i$ & Pontevedra & 37914 & 4713162 & 107 & $89 \%$ & $74 \%$ \\
\hline $16 \mathbf{i}$ & Quintanar de la Orden & 497424 & 4383363 & 691 & $94 \%$ & $60 \%$ \\
\hline $17 \mathbf{i}$ & Saelices & 214128 & 4503179 & 680 & $85 \%$ & $93 \%$ \\
\hline $18 \mathrm{c}$ & San Sebastián & 585143 & 4796553 & 63 & $95 \%$ & $98 \%$ \\
\hline $19 \mathrm{c}$ & Santander & 435306 & 4814764 & 52 & $84 \%$ & $77 \%$ \\
\hline $20 \mathrm{i}$ & Sevilla & 232939 & 4143520 & 11 & $90 \%$ & $81 \%$ \\
\hline $21 \mathbf{i}$ & Soria & 544303 & 4624044 & 1082 & $95 \%$ & $76 \%$ \\
\hline $22 \mathrm{i}$ & Talavera la Real & 167495 & 4310781 & 190 & $84 \%$ & $97 \%$ \\
\hline $23 \mathrm{c}$ & Tarifa & 265693 & 3988961 & 41 & $84 \%$ & $88 \%$ \\
\hline $24 c$ & Tenerife & -803678 & 3219700 & 35 & $80 \%$ & $91 \%$ \\
\hline $25 \mathrm{i}$ & Teruel & 659442 & 4468481 & 915 & $92 \%$ & $96 \%$ \\
\hline C1i & Ascó & 798882 & 4567276 & 94 & $97 \%$ & $64 \%$ \\
\hline $\mathrm{C} 2 \mathrm{c}$ & Barcelona & 930831 & 4595065 & 65 & $98 \%$ & $98 \%$ \\
\hline C3i & Girona & 982975 & 4662313 & 101 & $96 \%$ & $52 \%$ \\
\hline $\mathrm{C} 4 \mathrm{i}$ & Lleida & 799896 & 4614775 & 183 & $92 \%$ & $97 \%$ \\
\hline C5i & Puigcerdà & 905425 & 4709486 & 1207 & $93 \%$ & $40 \%$ \\
\hline C6c & Roses & 1008934 & 4714978 & 61 & $96 \%$ & $98 \%$ \\
\hline C7c & Tarragona & 856839 & 4560546 & 48 & $93 \%$ & $92 \%$ \\
\hline $\mathrm{C} 8 \mathrm{c}$ & Vandellós & 825835 & 4541261 & 11 & $93 \%$ & $98 \%$ \\
\hline C9i & Vielha & 808944 & 4731064 & 1402 & $92 \%$ & $95 \%$ \\
\hline
\end{tabular}

\section{Results and discussion}

\subsection{Average concentrations}

Following the behaviour of radon progeny concentration a classification into two main groups, named coastal (c) and inland (i) sites has been established. Furthermore, within the inland group there is a singular station, Penhas Douradas, which must be studied separately due to its location on the ridge of a 
high mountain. Table 2 shows typical radiological mean values estimated at each station type including wind velocity and predominant wind direction for the three-year period, and the yearly averaged radon progeny air concentration is shown in figure 3.

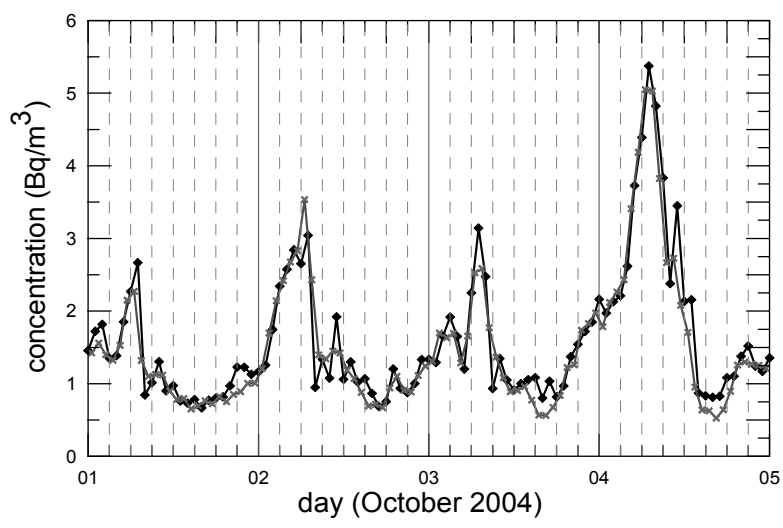

Figure 2: $\quad$ Comparison of the LB BAI 9850 minus one-hour corrected output values $(\mathbf{X})$ and the INTE alpha spectrometer output values $(\bullet)$.

The stations at Motril (11c) for coastal and Lugo (9i) for inland have been chosen in order to represent the behaviour of sites belonging to both groups. The Penhas Douradas (14i-m) site has also been taken as a representative station because of its particular mountain behaviour.

\subsection{Diurnal behaviour}

The daily variation of radon progeny concentration has been studied over the three-year period. Figure 4 and 5 show the behaviour of the hourly averaged concentrations at the chosen stations. The well-known daily variation described in the tutorial work of Porstendörfer [5] with a maximum in the early hours of the morning and a minimum at noon can be seen both in coastal and general inland sites with lower mean values at coastal sites because of the influence of the sea. This cyclic behaviour is mainly due to the heating of the ground during the sunny hours of the day, which produces the development of a well-mixed boundary layer, followed by the cooling of the ground at night. The surface cooling implies the suppression of turbulence of the air above and the appearance of a stable nocturnal boundary layer that prevents the dispersion of radon and its decay products. Nevertheless, figure 6 shows that the Penhas Douradas station follows an inverse behaviour due to the influence of mountain mesoscale phenomena. Similar behaviour has been seen, for instance, for ${ }^{214} \mathrm{~Pb}$ in the work of Gäggeler et al. [6]. This particular site and its radon progeny concentration temporal variation are currently under study using the MM5 mesoscale model, Dudhia [7], and FLEXPART dispersion model, Stohl et al. [8]. 
Table 2: $\quad$ Radon progeny concentration geometric mean (Rn-P GM) and arithmetic mean (Rn-P AM), mean wind velocity, mean dose rate and predominant wind direction for all the REA stations.

\begin{tabular}{|c|c|c|c|c|c|c|}
\hline $\begin{array}{c}\text { Station } \\
\text { label }\end{array}$ & $\begin{array}{c}\text { Rn-P (GM) } \\
\text { Bq/m3 }\end{array}$ & $\begin{array}{c}\text { Rn-P (AM) } \\
\text { Bq/m3 }\end{array}$ & $\mathrm{T}^{\circ} \mathrm{C}$ & $\begin{array}{l}\mathbf{W V} \\
\mathrm{m} / \mathrm{s}\end{array}$ & $\begin{array}{l}\text { Dose rate } \\
(\mu \mathrm{Sv} / \mathrm{h})\end{array}$ & $\begin{array}{l}\text { Dominant } \\
\text { WD }\end{array}$ \\
\hline $1 \mathrm{i}$ & 2.296 & 3.275 & 12.87 & 1.95 & 0.138 & $\mathrm{~W}$ \\
\hline $2 \mathrm{i}$ & 4.633 & 8.271 & 11.94 & 1.03 & 0.149 & W \\
\hline $3 \mathbf{i}$ & 4.289 & 7.882 & 17.40 & 1.76 & 0.133 & W \\
\hline $4 i$ & 3.266 & 4.264 & 10.65 & 4.08 & 0.135 & E \\
\hline $5 c$ & 1.350 & 2.242 & 14.33 & 0.83 & 0.115 & SW \\
\hline $6 i$ & 3.350 & 5.154 & - & - & 0.194 & - \\
\hline $7 c$ & 2.882 & 5.308 & 18.30 & 2.65 & 0.118 & NW \\
\hline $8 i$ & 2.347 & 2.347 & 11.58 & 1.91 & 0.169 & NW \\
\hline $9 \mathbf{i}$ & 3.493 & 6.161 & 9.94 & 1.93 & 0.137 & $\mathrm{~N} / \mathrm{S}$ \\
\hline $10 i$ & 5.484 & 9.858 & 16.69 & 2.39 & 0.200 & SW \\
\hline $11 \mathrm{c}$ & 1.983 & 2.635 & 17.29 & 2.07 & 0.132 & W \\
\hline $12 \mathrm{i}$ & 1.488 & 2.510 & 18.01 & 1.80 & 0.129 & E/NW \\
\hline $13 c$ & 1.383 & 1.699 & 18.27 & 1.64 & 0.157 & $\mathrm{~N} / \mathrm{S}$ \\
\hline $14 i-m$ & 2.312 & 3.635 & 10.31 & 3.69 & 0.264 & SE \\
\hline $15 c$ & 5.550 & 11.901 & 14.35 & 1.09 & 0.207 & $\mathrm{~S}$ \\
\hline $16 \mathrm{i}$ & 2.724 & 3.832 & 14.11 & 1.52 & 0.165 & SE \\
\hline $17 \mathbf{i}$ & 8.416 & 27.679 & 12.79 & 2.21 & 0.161 & $\mathrm{~W} / \mathrm{E}$ \\
\hline $18 \mathrm{c}$ & 3.572 & 4.675 & 14.26 & 1.29 & 0.114 & $\mathrm{~N}$ \\
\hline $19 c$ & 1.790 & 2.916 & 15.17 & 4.77 & 0.130 & SW \\
\hline $20 \mathrm{i}$ & 3.637 & 6.831 & 19.07 & 1.01 & 0.141 & $\mathrm{~N}$ \\
\hline $21 i$ & 2.733 & 3.994 & 10.83 & 2.46 & 0.186 & W \\
\hline $22 \mathrm{i}$ & 4.049 & 6.922 & 16.91 & 2.92 & 0.112 & W \\
\hline $23 c$ & 1.432 & 1.856 & 17.50 & 4.88 & 0.146 & E \\
\hline $24 \mathrm{c}$ & 0.838 & 1.245 & 20.92 & 1.91 & 0.129 & NW \\
\hline $25 \mathrm{i}$ & 3.433 & 5.914 & 11.65 & 1.58 & 0.131 & NW \\
\hline C1i & 3.608 & 6.361 & 16.94 & 2.50 & n. a. & $\mathrm{N}$ \\
\hline $\mathrm{C} 2 \mathrm{c}$ & 4.974 & 6.006 & 16.43 & 3.56 & n. a. & $\mathrm{NE}$ \\
\hline C3i & 7.521 & 10.888 & 16.61 & 1.49 & n. $a$. & $\mathrm{S}$ \\
\hline $\mathrm{C} 4 \mathrm{i}$ & 5.420 & 8.314 & 15.53 & 2.56 & n. a. & E \\
\hline C5i & 6.984 & 10.485 & 10.09 & 2.77 & n. a. & E \\
\hline C6c & 5.695 & 7.176 & 16.96 & 2.99 & n. a. & $\mathrm{NE}$ \\
\hline C7c & 4.014 & 4.969 & 17.53 & 3.16 & n. a. & NW \\
\hline C8c & 2.075 & 2.631 & 17.44 & 3.15 & 0.169 & NW \\
\hline C9i & 2.030 & 2.943 & 9.78 & 1.81 & n. a. & $\mathrm{S}$ \\
\hline
\end{tabular}

\subsection{Seasonal behaviour}

The three-year analysis of the monthly averaged radon progeny concentration shows a seasonal variation which agrees with the literature as can be seen, for instance, in the work of Baciu [9], with higher values at the end of summer and beginning of autumn and lower values from spring to early summer due to seasonal variations of atmospheric stability as can be observed in figure 7 .

\subsection{Polar behaviour and geological influence}

The geological characteristics of the station influence the radon progeny air concentration since radon exhalation from the soil depends upon radium concentration in rocks and their permeability. Furthermore, for a correct interpretation of the values obtained at each station it is not enough to take into account just the lithology at the site but its surroundings due to atmospheric transport of radon and radon progeny. 


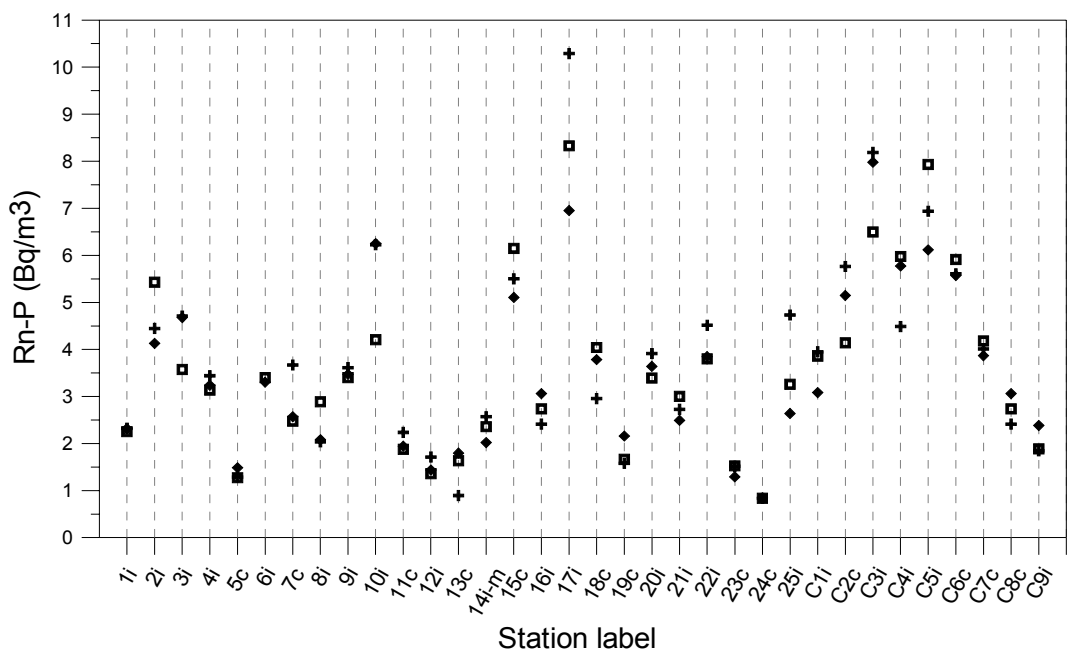

Figure 3: Radon progeny concentration geometric mean (Rn-P) for each station corresponding to the years $2000(+), 2001(\boldsymbol{\square})$ and 2002( $)$.

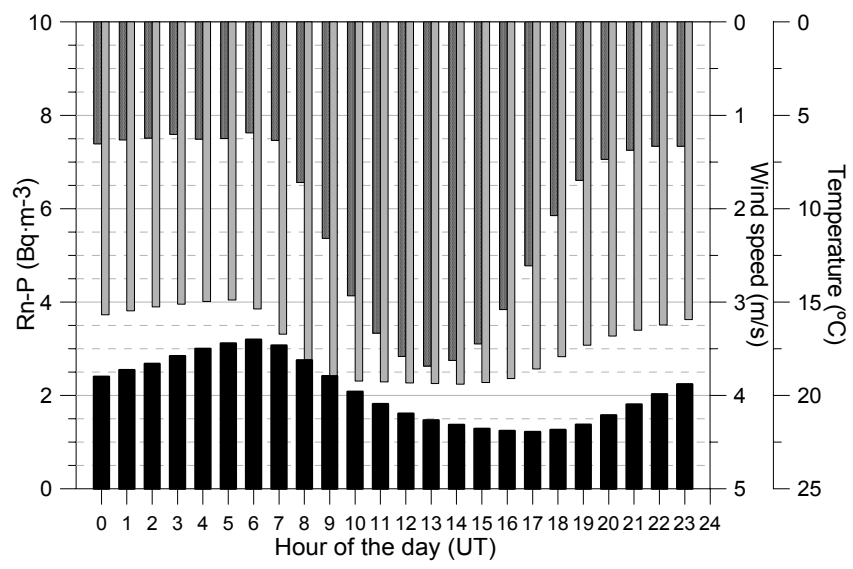

Figure 4: Daily behaviour of the mean radon progeny concentration Rn-P $(\square)$, wind speed ( $\square)$ and temperature ( $\square)$ at the $11 \mathrm{c}$ coastal site.

The polar distribution of radon progeny concentration related to wind direction and velocity has been analysed for the three-year period. Figure 8 shows the influence of different exhalation rate regions of the two reference station surroundings. At the coastal station, the non-significant radon exhalation of the sea, located to the south, leads to low values of radon progeny concentration in that direction, while at the inland station higher values to the south-east and north-west are appreciated due to geological lithology of its 
surroundings. At both stations there is a general decrease of direction dependence when wind velocity is low.

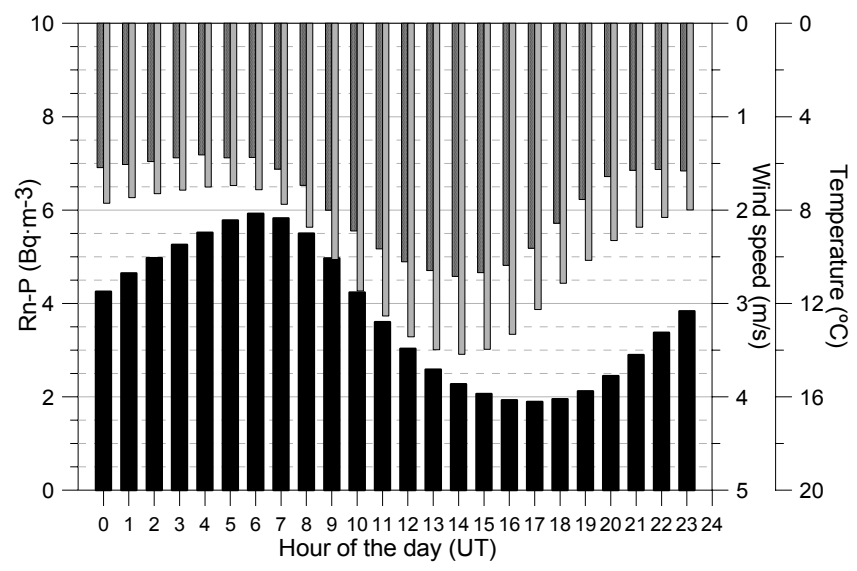

Figure 5: Daily behaviour of the mean radon progeny concentration Rn-P

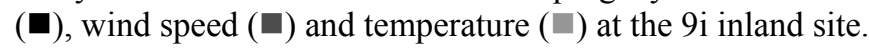

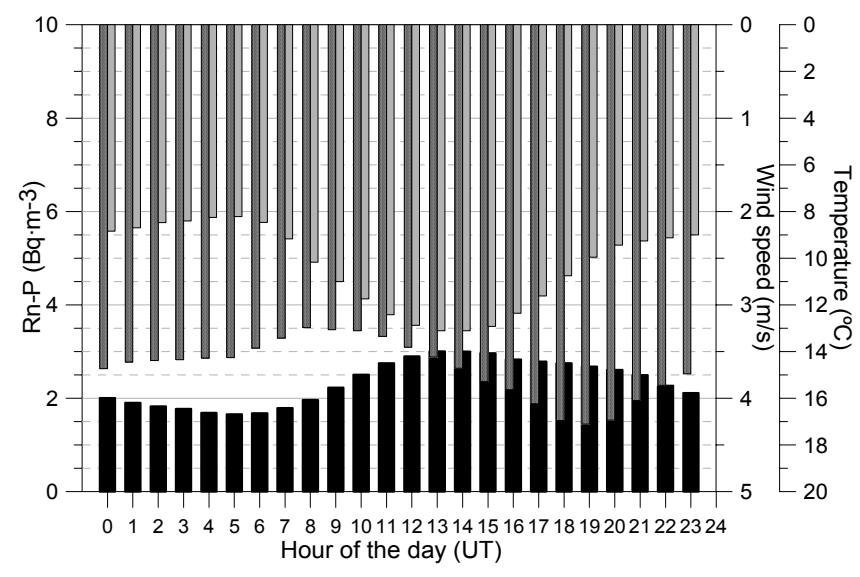

Figure 6: Daily behaviour of the mean radon progeny concentration Rn-P $(\boldsymbol{\square})$, wind velocity $(\square)$ and temperature $(\square)$ at the $14 \mathrm{i}-\mathrm{m}$ inlandmountain site.

\section{Conclusions}

This study has shown the importance of accurate characterization of the natural aerosol radioactivity at the station sites of a radiological surveillance network to evaluate artificial radioactive aerosol concentration.

Time evolution of the planetary boundary layer (PBL) and also the meteorological parameters, determine the transport of radon and its decay 
products. The daily cycle of radon progeny concentration presents a maximum in the early morning with the exception of the Penhas Douradas site, which presents an inverse cycle due to its location on a mountain ridge. There is also a seasonal pattern with minimum values during the spring months due to the high atmospheric instability, typical of this season, which increases turbulent mixing of radon decay products within the PBL. Some directional dependence in radon progeny concentration related to the geological surrounding of the station site has also been appreciated.

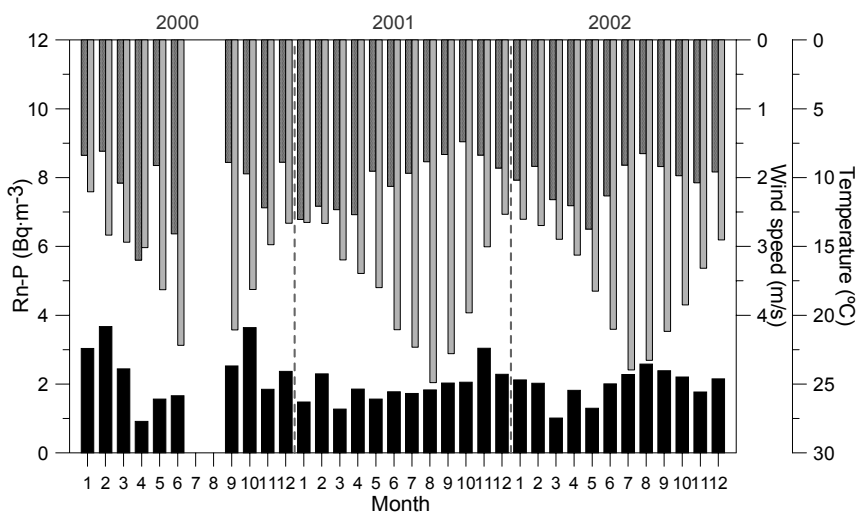

Figure 7: Monthly averaged radon progeny concentration ( $\mathbf{\square})$, wind speed $(\square)$ and temperature $(\square)$ at the $11 \mathrm{c}$ coastal site.
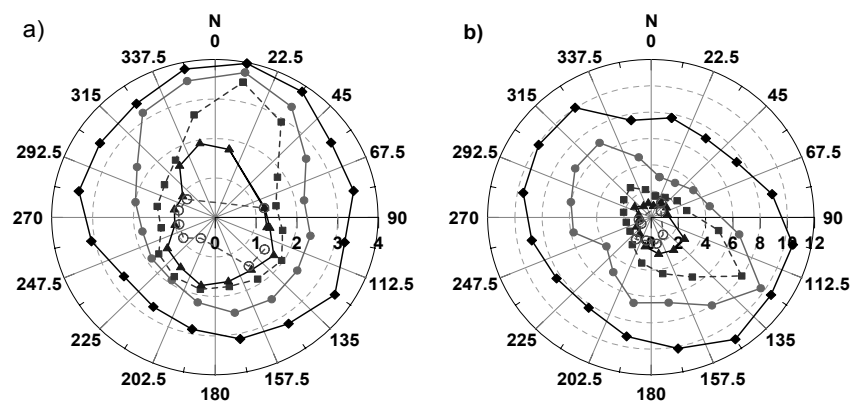

Figure 8: Polar distribution of radon progeny concentration divided into wind velocity categories, $\mathrm{v} \leq 0.3 \mathrm{~m} / \mathrm{s}(\diamond), 0.3<\mathrm{v} \leq 1 \mathrm{~m} / \mathrm{s}(\bullet), 1<\mathrm{v} \leq 3 \mathrm{~m} / \mathrm{s}(\square)$, $3<\mathrm{v} \leq 5 \mathrm{~m} / \mathrm{s}(\boldsymbol{\Delta}), \mathrm{v}>5 \mathrm{~m} / \mathrm{s}(\mathrm{O})$ for a) coastal and b) inland sites.

It is planned to use the MM5 mesoscale meteorological model and the FLEXPART dispersion model to simulate typical meteorological conditions often occurring in the Iberian Peninsula and their influence on radon progeny dispersion. Moreover the radon source will be estimate using the geological information provided by the Instituto Geológico y Minero de España (IGME) [10]. 


\section{Acknowledgements}

This work has been supported by the Spanish Education and Science Ministry (MEC) through the project REN2002-01994.

The Spanish Nuclear Council (CSN) and the Radioactive Activities Control Service (SCAR) have provided the three-year data set.

\section{References}

[1] CSN, www.csn.es.

[2] Vila, M., Lardiez, P., Lentijo, J.C. Red de estaciones automáticas de vigilancia radiológica ambiental (REA) del CSN. Operación y resultados Años 2000 y 2001. Colección de informes Técnicos 8.2002, 2002.

[3] INM, www.inm.es

[4] Vargas, A., Ortega, X., Cortés, G., Bonet, J., Response of a radioactive aerosol monitor to radon progeny concentration. IRPA 11 ABSTRACTS. Eds Senda editorial, S.L., pp. 246-246, 2004.

[5] Porstendörfer, J. Properties and behaviour of radon and thoron and their decay products in the air. J. Aerosol Sci., Vol. 25, No.2, pp. 219-263, 1994.

[6] Gäggeler, H. W., Jost, D. T., Baltensperger, U., Schwikowski and Seibert, $\mathrm{P}$. Radon and thoron decay product and ${ }^{210} \mathrm{~Pb}$ measurements at Jungfraujoch, Switzerland. Atmospheric Environment, Vol. 29, No 5, pp. 607-616,1995.

[7] Dudhia, J. A nonhydrostatic version of the Penn State / NCAR mesoscale model: Validation tests and simulations of an Atlantic cyclone and cold front. Mon. Wea. Rev., 121, pp. 1493-1513, 1993.

[8] Stohl, A., M. Hittenberger and G. Wotawa. Validation of the Lagrangian particle dispersion model FLEXPART against large scale tracer experiment data. Atmos. Environ, 24, 4245-4264, 1998.

[9] Baciu, A.C. Radon and thoron progeny concentration variability in relation to meteorological conditions at Bucharest (Romania). J. Environ. Radioact. 83, pp. 171-189, 2005.

[10] IGME, www.igme.es. 